\title{
Impact of Geometry Parameters of a Sliding Surface of a Bearing on Tribological Characteristics of Sliding Bearings
}

\author{
Radosław Michalak ${ }^{1}$
}

Received: 24 July 2017 / Accepted: 9 May 2018 / Published online: 23 May 2018

(C) The Author(s) 2018

\begin{abstract}
One of the characteristic parameters which is important for functioning of a journal bearing is relative clearance which has a direct impact on the bearing performance during an initial run-in period and standard operation. An equally important aspect is the proper selection of journal and bearing materials, as it ensures their proper cooperation, i.e., possibly low coefficient of friction, low resistance to motion and minimal wear. Another important issue is the geometry of the working surface of the bearing, i.e., giving it a proper shape by the use of lubricating microgrooves (micro-channels) which support the formation of an oil film. Forming a sliding surface in such a manner contributes to a better cooperation between the journal and the bearing. The paper presents the results of tribological tests, specifically the impact of the use of two types of lubricating microgrooves, made on the internal surface of the bearing on tribological characteristics. The tests were conducted for journal bearings composed of the bearing coated with casted $\mathrm{SnSb} 12 \mathrm{Cu} 6 \mathrm{~Pb}$ alloy and the steel journal. During the tests, the friction torque, bearing temperature and voltage drop on the internal resistance of oil film were registered. As a result of the investigation, it was noticed that the use of rounded lubricating microgrooves has a positive effect on the tribological characteristics and can contribute to increasing the load-bearing capacity and durability of the journal bearings.
\end{abstract}

Keywords Friction $\cdot$ Journal bearing $\cdot$ Lubrication $\cdot$ Microgrooves $\cdot$ Tribology $\cdot$ Wear

\section{Introduction}

In the friction parts of machines and devices, there are commonly used conventional sliding bearing systems, namely journal bearing with a smooth working surface. Depending on the application, this journal bearing has to possess an appropriate construction and capability. The process and design procedures are very complicated and demanding tasks (Martin and Garner 1983; Chen et al. 2012).

A very important element responsible for the correct operation of the sliding bearing is the formation of an oil film with the aid of a lubricant. The lubricant in the form of oil must have suitable properties among which the

Radosław Michalak

radoslaw.michalak@p.lodz.pl

1 Department of Vehicles and Fundamentals of Machine

Design, Lodz University of Technology, 1/15

Stefanowskiego St, 90-924 Lodz, Poland viscosity is the most important. The viscosity of the lubricant has a great influence on the quality of the lubrication of the bearing and thereby its durability (Wang and Lu 2015). Apart from the usual lubricating oils, lubricants based on oils containing granular particles can also contribute to increasing the efficiency of the sliding bearings (Rahmani and Jayanta 2016).

In applications where these kinds of journal bearings are used, the oil film formation process is affected by the macro- and microgeometry parameters of the cooperating parts.

As for the macrogeometry, the radial clearance, which has a direct influence on the friction torque in such a system, may be considered (Bouyer and Fillon 2011). Another very important aspect during the operation of sliding bearing is its start-up and subsequent phases of transition from mixed-film lubrication to full-film lubrication, which directly affect the friction torque in the bearing and thus its durability (Bouyer and Fillon 2011). In addition to the well-known and commonly used bearing materials, 
additional layers are also applied to the surface of the bearing or the journal (Wójcicki and Strzelecki 1999; Kagohara et al. 2009). These layers have great potential for reducing friction losses, i.e., they provide lower adhesion forces between the cooperating elements, which translate into favorably lower values of coefficient of friction.

All those variables have a significant influence on the tribological characteristics of the sliding bearings durability and wear rate.

In case of the microgeometry, the so-called circumferential and axial waviness of the bearing working surface is used (Hassan and Rasheed 1998). The corresponding shape may result in increased load capacity and reduced friction torque in the journal bearing.

Moreover, in addition to the suitable relative clearance and proper choice of the journal and bearing materials an important issue is the geometry of the surfaces cooperating in the sliding bearing. In other words, the surface may be textured by the formation of lubrication microgrooves. This kind of surface shaping (texturing) can have a direct effect on the improvement in friction torque and uniform temperature distribution (Tala-Ighil and Fillon 2015). Such a surface texture is also intended to protect the bearing by trapping harmful particles contaminating the lubricant and causing accelerated wear (Azzedine and Conlon 2016). Following Korzynski (2009), these microgrooves may be formed using the burnishing method. Nevertheless, all methods of shaping the sliding surface may positively affect the formation of the oil film and at the same time change the working conditions between the cooperating elements.

The aim of the presented work was to analyze the influence of two types of microgrooves with different shape and geometry, created on the sliding surface of the bearing, on the friction torque, bearing temperature and oil film formation during the operation of the journal bearing. The tests were carried out for a relative clearance with values characteristic of sliding bearings working with lubricants.

\section{Experimental Procedure}

\subsection{Characteristics of Bearings}

The bearings were coated with $1 \mathrm{~mm}$ thick layer of SnSb12Cu6Pb alloy (according to PN-ISO 4381:1997). Length-to-diameter ratio of the bearing was equal to 0.25 . The bearings were cooperating with journals made of hardened steel with a hardness of 55HRC and surface roughness $R \mathrm{a}=0.2-0.3 \mu \mathrm{m}$. On the surface of the bearings, microgrooves were created in two configurations. Both types of the microgrooves are presented in Fig. 1.
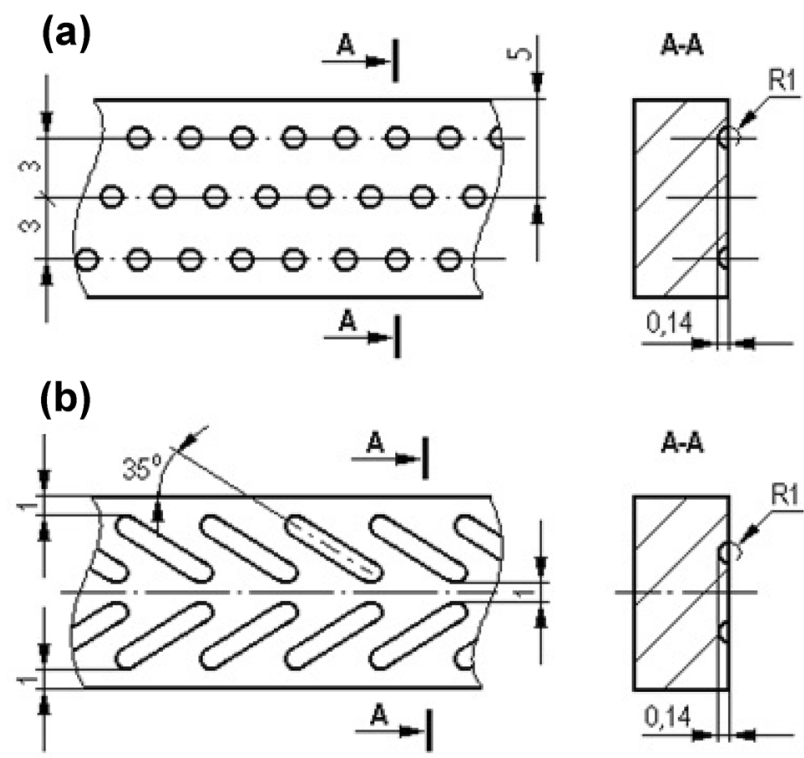

Fig. 1 Geometry of the microgrooves: a rounded and $\mathbf{b}$ diagonal

The proposed configurations of the microgrooves, on the inner surface of the bearings, were modeled and subsequently produced on a CNC milling machine by machining. In the case of rounded microgrooves of a total amount of 153, the percentage of the surface of microgrooves relative to the total surface of the bearing is $\approx 11 \%$, whereas for the diagonal ones in quantity of 102 , the percentage of the surface of microgrooves relative to the total surface of the bearing is $\approx 40 \%$.

The regular bearing coated with $\mathrm{SnSb} 12 \mathrm{Cu} 6 \mathrm{~Pb}$ alloy without the microgrooves was also examined for comparison.

\subsection{Description of the Test Stand}

Tribological characteristics were performed at the test stand in the Department of Vehicles and Fundamentals of Machine Design, Lodz University of Technology (Figs. 2,

3) (Michalak and Wójcicki 2012a, b, 2013).

The test stand is equipped with the following systems of control-measurement and coordination:

- journal rotation speed control system,

- system of control and measurement of a lubricating unit,

- friction torque measuring system (the measuring channel marked in the characteristics as $\mathrm{k} 8$ ),

- system of measuring the friction conditions at the contact point of the bearing and the journal (the measuring channel marked in the characteristics as k1),

- system of measurement of the bearing and the supplying oil temperature (the measuring channel marked in the characteristics as $\mathrm{k} 3-\mathrm{k} 5$ ). 
Fig. 2 Schematic of the test stand where: $A, B$ and $C$ are: the drive motor, the oil pump and the stirrer of the oil temperature control unit, respectively; and sensors: 1 -rotation speed and the number of journal revolutions, 2-force measurement, $3,4,5,6,7-$ temperatures and 8 -oil pressure

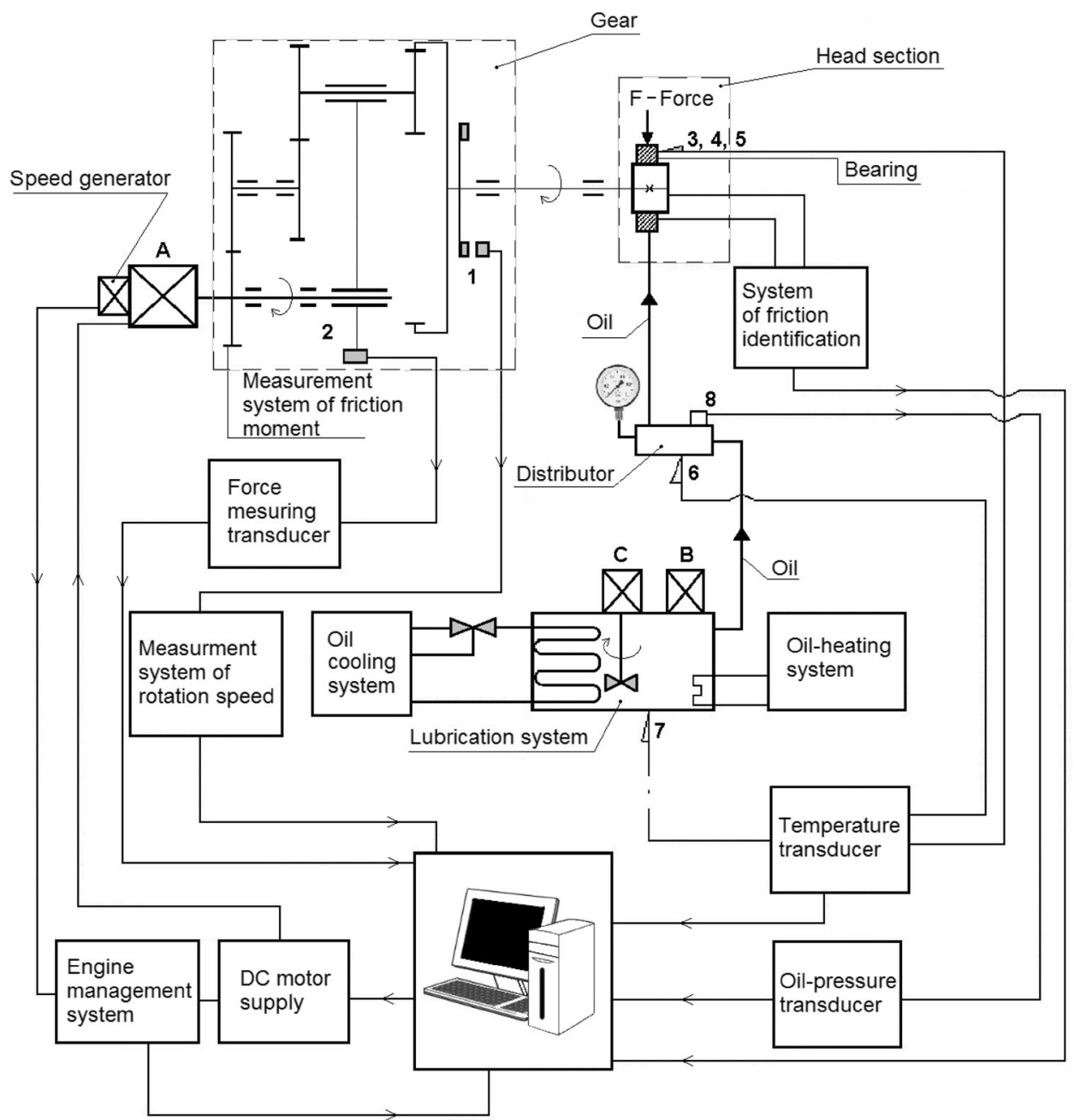

The basic component of the journal rotational speed control system includes a DC motor. The rotation speed " $n$ " of the journal is controlled by a DC motor in the range of $0-350 \mathrm{rpm}$. The system of control and measurement of the lubricating unit with the electronic stabilization module helps to maintain the desired temperature (from about 16 to $\left.120^{\circ} \mathrm{C}\right)$ and the pressure of lubricant $(0-0.4 \mathrm{MPa})$. The system of measurement of friction torque in the sliding bearing makes it possible to observe changes of this parameter.

The friction torque in the journal bearing is recorded as the difference between the friction torque in the tested sliding bearing and the torque of resistance of the test head movement (reference torque) when idling the test bench. The friction contact condition evaluation system, by the continuous measurement of the voltage drop on the internal resistance of the oil film, enables the assessment of the friction conditions in the friction node $(100 \%$ liquid friction $=100 \mathrm{mV}, 50 \%$ mixed friction $=50 \mathrm{mV}, 0 \%$ dry friction $=0 \mathrm{mV}$ ).
The temperature measurement system registers the temperature at three characteristic points. Measuring points are located on the outer side of the bearing, but opposite to the point where the journal meets the bearing. These points were called conventionally: the beginning, the middle and the end of the contact between the bearing and the journal. The temperature measurement is carried out using three $\mathrm{NiCr}-\mathrm{Ni}$ thermocouples with a diameter of $0.5 \mathrm{~mm}$ (Figs. 2, 3c).

\subsection{Tribological test conditions}

In Fig. 4, a way of loading the test head is presented schematically. A transverse load on the journal bearing " $F$ " is applied to the stationary bearing through the head section. The load value is adjustable in the range between 200 and $2000 \mathrm{~N}$.

During the operation of journal bearings, adverse working conditions occur, which may be the reason of mixed friction. In order to enable the journal bearing to work in such unfavorable conditions, the apparatus enables 
(a)

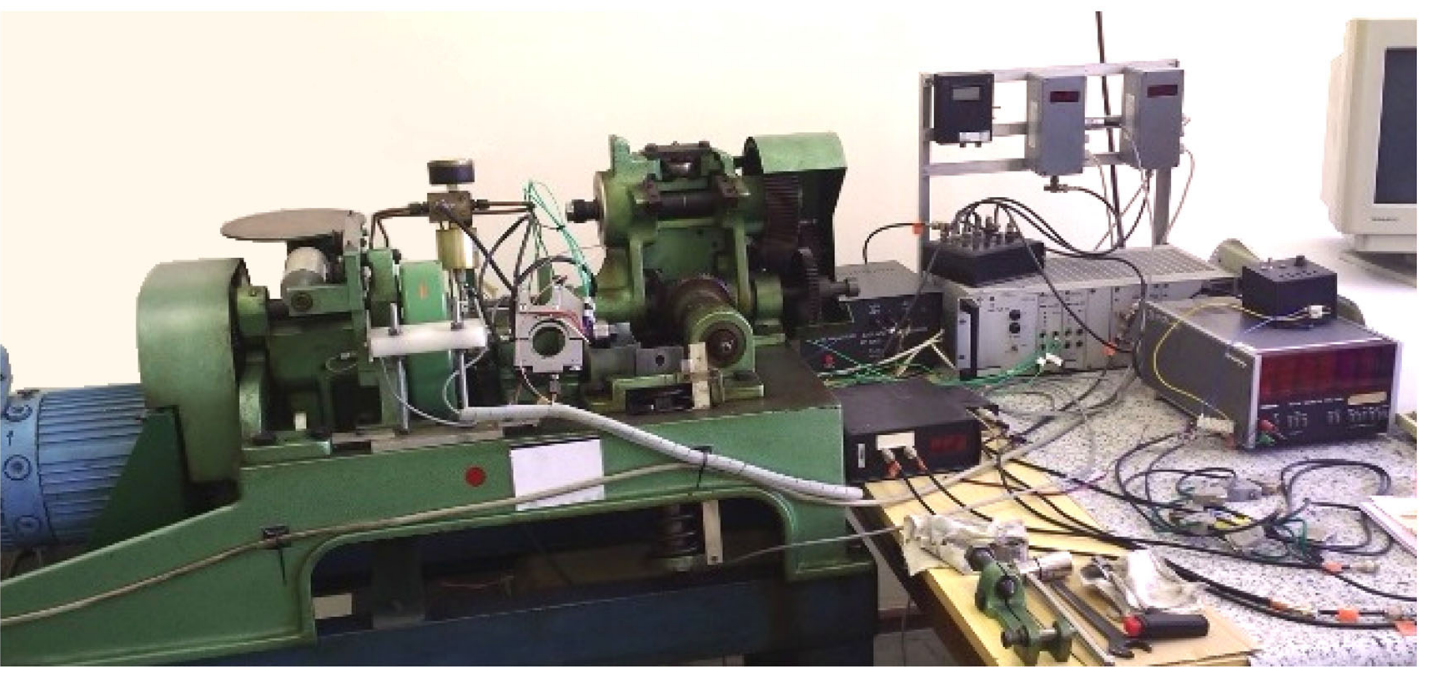

(b)

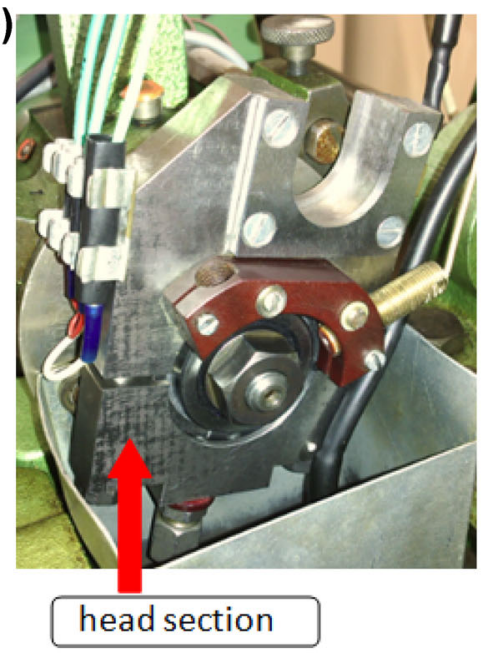

(c)

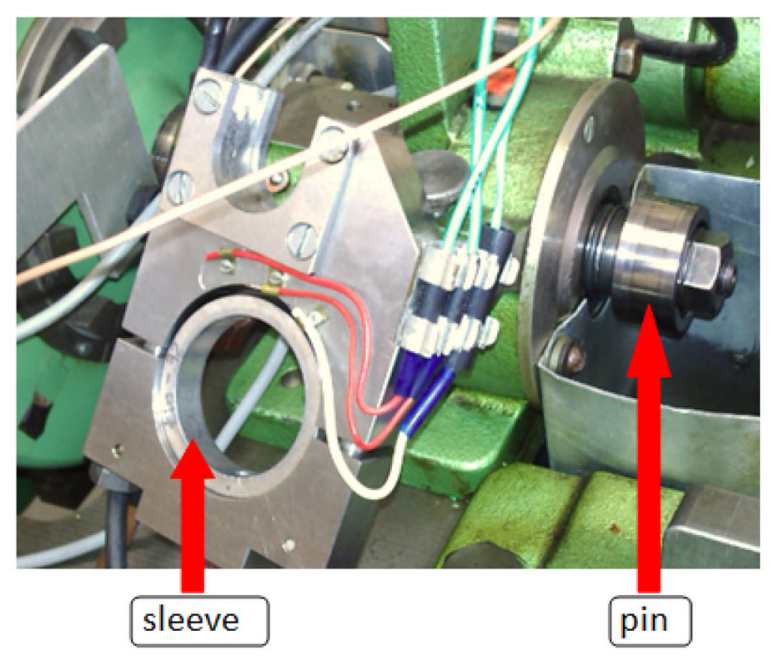

Fig. 3 View of the test stand: a general view with control and measurement system; $\mathbf{b}$ head section; and $\mathbf{c}$ disassembled head section with visible bearing and thermocouples

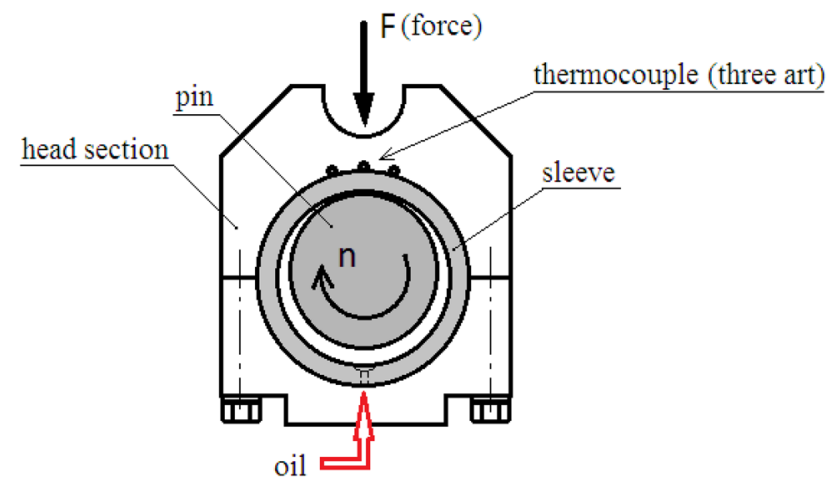

Fig. 4 Schematic of the head section of the test stand

changing the rotation speed. A sample of the test cycle is shown in Fig. 5. The variable rotation speed in a given cycle is repeated in series of 40 tests.
The tests of a given friction couple start with a preliminary run-in period under the transverse load of $200 \mathrm{~N}$ (for which the equivalent pressure in the journal bearing corresponds to $0.5 \mathrm{MPa}$ ). After the run-in period, the proper test is conducted, according to the cycle presented in Fig. 4, for the transverse load of $400 \mathrm{~N}$ (equivalent pressure in the bearing corresponds to $1 \mathrm{MPa}$ ). The pressure in the journal bearing results from the transverse load of the bearing and the projection of the bearing surface on the plane. In the initial phase, there is a start-up period, i.e., a gradual increase in the rotational speed " $n$ " of the journal to $350 \mathrm{rev} / \mathrm{min}$ within a time of $60 \mathrm{~s}$, for the next $60 \mathrm{~s}$ the steady operation is in progress, and then within $60 \mathrm{~s}$ the operation of the tested sliding bearing set stops. This cycle is repeated for 40 series. The other parameters during the tests are as follows: temperature of the oil supplying the bearing $22-24{ }^{\circ} \mathrm{C}$, oil pressure $0.05 \mathrm{MPa}$, the tests are conducted under ambient temperature of $24{ }^{\circ} \mathrm{C}$. 
Fig. 5 A sample presenting the rotation speed of the journal during one test cycle

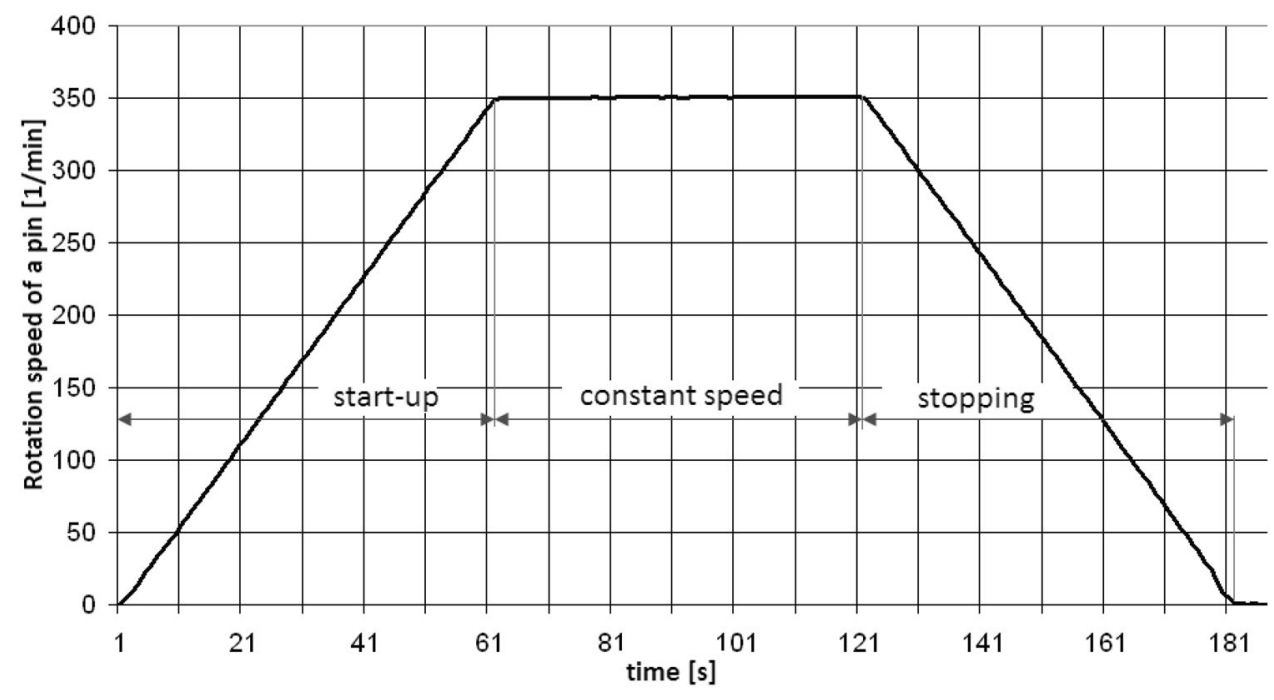

\section{Results and Discussion}

In Figs. 6 and 7, images of bearings with two types of microgrooves are presented before and after the tests.

There are noticeable differences in the wear of surfaces modified with both types of microgrooves after 40 cycles of the tests. The diagonal microgrooves negatively affected the formation of the oil film, which is visible at the bottom of the surface of the bearing, where the diagonal microgrooves are completely worn out. In case of the bearing with rounded microgrooves, there is no visible wear and all microgrooves are visible, which may suggest much better lubricating conditions.

Figure 8 presents a comparison of the friction torque for the average pressure of $1 \mathrm{MPa}$.

The differences in the values of friction torque between all three examined types of bearings clearly show the advantage of both, the one with rounded microgrooves and the flat one as well.

Based on the registered characteristics, it is clear that for the bearing with diagonal microgrooves, the average value

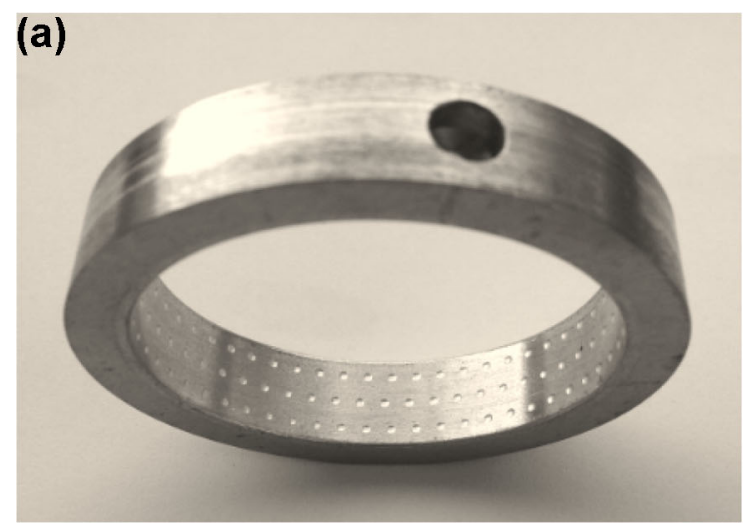

of the friction torques is the highest. For bearing with a smooth surface, the value of the friction torque amounts to $\approx 0.2 \mathrm{Nm}$, whereas in case of the one with rounded microgrooves the friction torque was the lowest, with a value $\approx 0.15$. The registered values of the friction torque (observed for the bearing with rounded microgrooves) are the result of the sufficient formation of the oil film, ensuring liquid friction between the cooperating journal and the bearing.

Figure 9 presents a comparison of temperatures at the beginning, the middle and the end of the contact between the bearing and the journal. On the basis of these characteristics, it can be observed that, in the bearing with rounded microgrooves, the temperatures near the beginning, the center and the end of the contact point is significantly lower in comparison with temperatures of other bearings subjected to the tests. The average temperature value for these three points was $\approx 24{ }^{\circ} \mathrm{C}$. Moreover, during the whole test, the temperature in this bearing showed the lowest fluctuations.

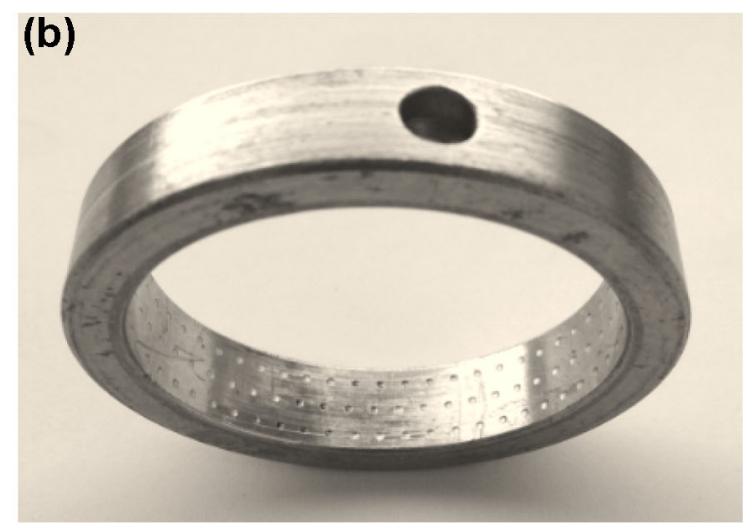

Fig. 6 Image of the bearing with rounded microgrooves: a before the tests and $\mathbf{b}$ after 40 cycles of the tests 

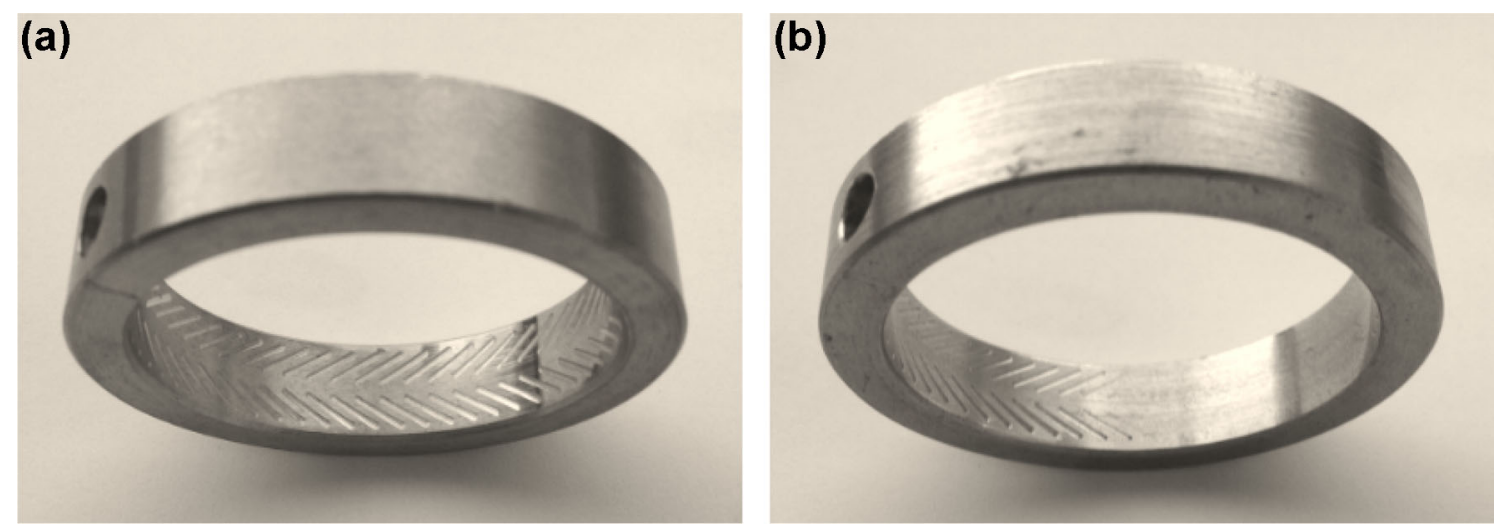

Fig. 7 Image of the bearing with diagonal microgrooves: a before the tests and $\mathbf{b}$ after 40 cycles of the tests

Fig. 8 The average values of friction torque for the tested bearings
Friction moment in a bearing-k8 (average values) for pressure 1MPa

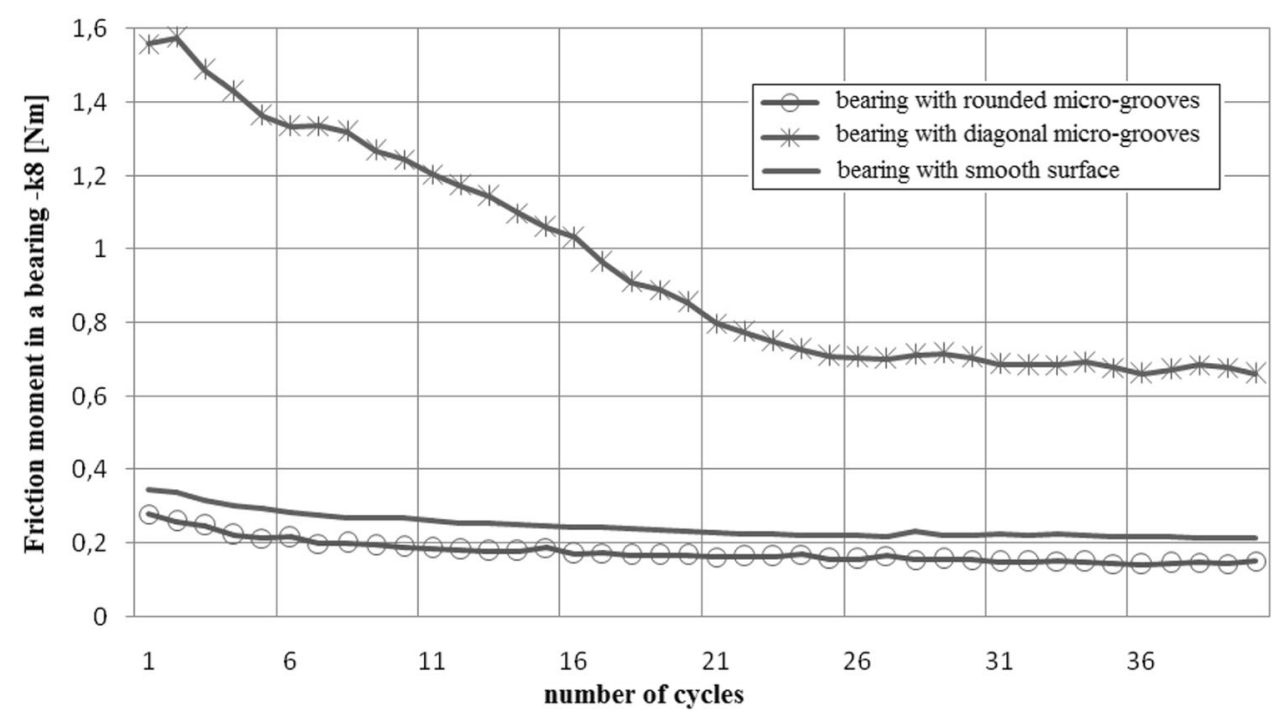

Figure 10 presents a comparison of the average values of the voltage drop on the resistance of the oil film for a pressure of $1 \mathrm{MPa}$. The registered characteristics show that the best conditions for formation of the oil film can be observed in case of the bearing modified with the rounded microgrooves. In this case, the average value of the voltage drop was $\approx 53 \mathrm{mV}$. For the bearing with diagonal microgrooves and with the smooth surface, the average value of the voltage drop is similar and comes to $\approx 9 \mathrm{mV}$. The highest values of the voltage drop on the inner resistance of the oil film were registered for the bearing with the rounded microgrooves. This observation is confirmed by the results of other tests and may indicate an optimal geometry of the lubrication microgrooves, which favors the formation of the oil film. In case of the diagonal microgrooves, their geometry strongly affects the formation of the oil film and deteriorates the conditions of cooperation between the journal and bearing.

\section{Conclusions}

Based on the obtained research results and comparative studies of the registered characteristics, it may be concluded that the use of diagonal microgrooves causes interference in the formation of the oil film, the increase in the friction torque and the temperature, mainly at the beginning of the cycle. The examined shape and configuration of the diagonal microgrooves on the surface of the bearing led to excessive wear after 40 series. On the other hand, the use of rounded microgrooves made it possible to obtain better values of all examined parameters which include: the lowest value of the friction torque among all the examined samples, similarly the lowest average temperature of the contact point between the journal and the bearing and noticeably higher average value of the voltage drop on the inner resistance of the oil film as compared to the other examined sliding bearing sets. 


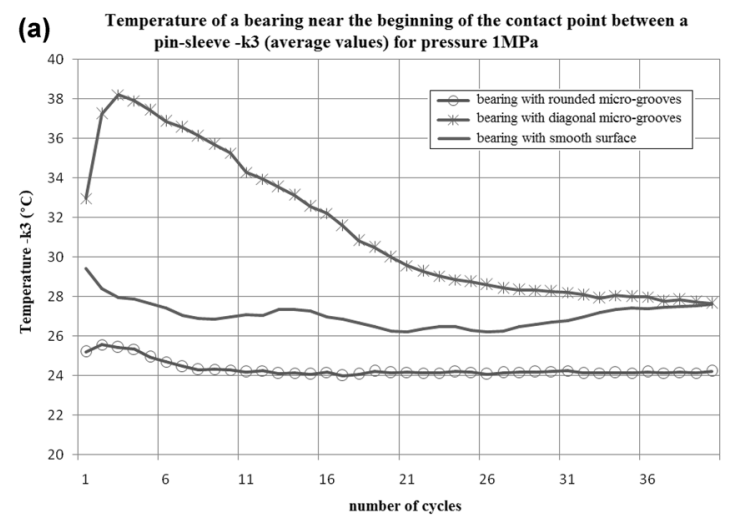

(b) Temperature of a bearing near in the middle of the contact point between a pin-

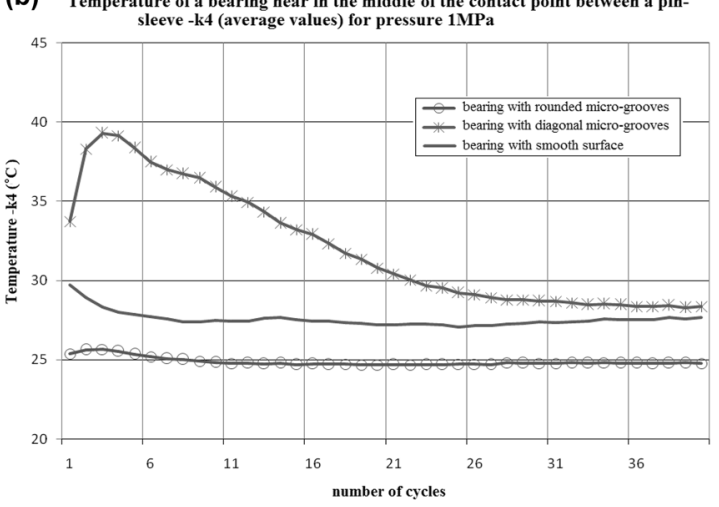

(c) Temperature of a bearing near the end of the contact point between a pin-sleeve $-\mathrm{k} 5$ (average values) for pressure $1 \mathrm{MPa}$

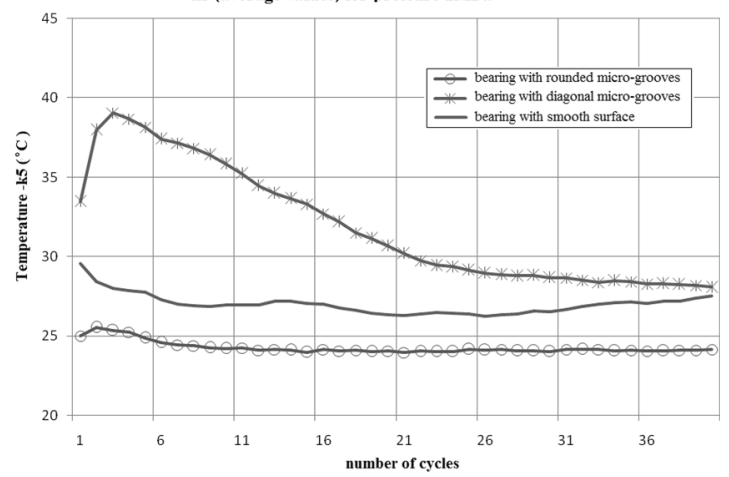

Fig. 9 The average values of temperature near the contact point of the journal and the bearing measured in three positions: a at the beginning; $\mathbf{b}$ in the middle; and $\mathbf{c}$ at the end of contact point

Fig. 10 The average values of a voltage drop on the inner resistance of an oil film
Average voltage drop at the contact point -k1 (average values) for pressure $1 \mathrm{MPa}$

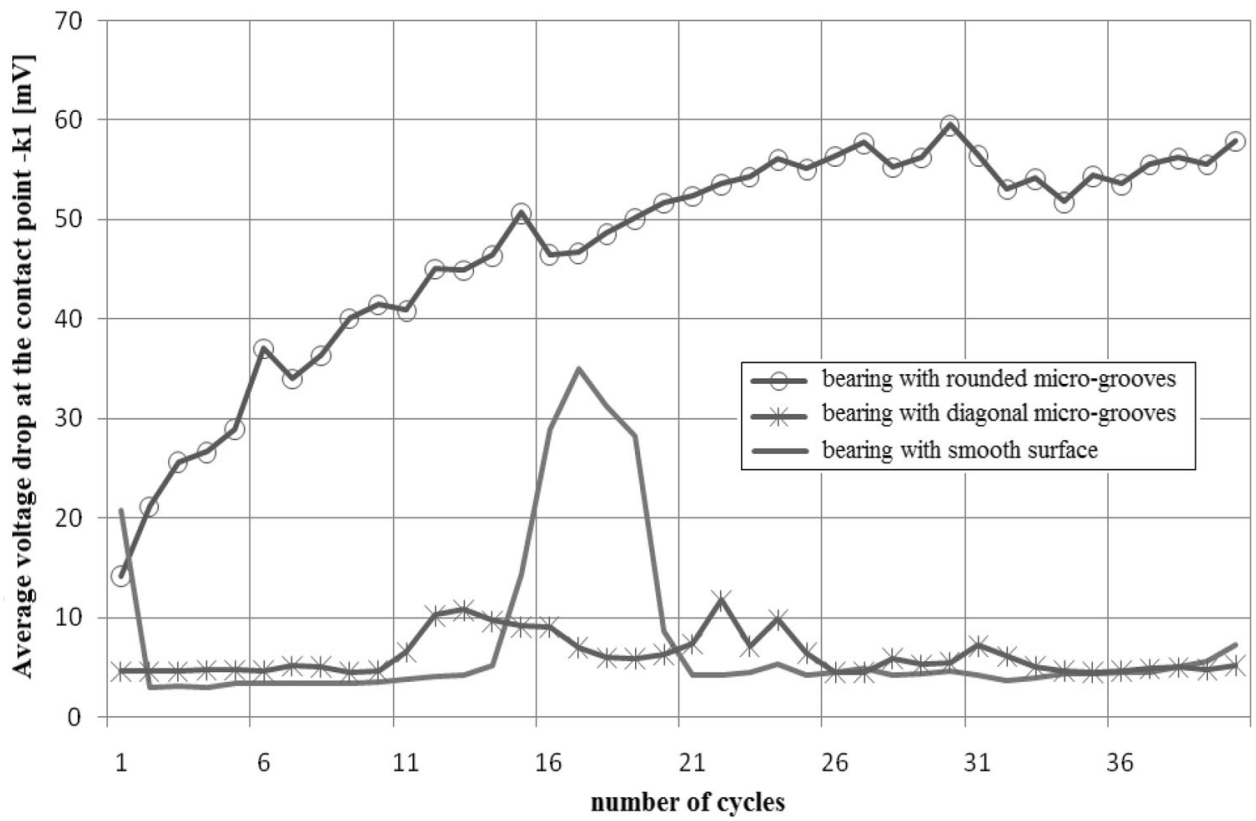

The positive influence of the rounded microgrooves on the tribological characteristics can contribute to increasing the load-bearing capacity and durability of the journal bearings. Further research is being carried out to determine even more favorable geometry of the rounded microgrooves (diameter, depth and surface distribution). 
Open Access This article is distributed under the terms of the Creative Commons Attribution 4.0 International License (http://creative commons.org/licenses/by/4.0/), which permits unrestricted use, distribution, and reproduction in any medium, provided you give appropriate credit to the original author(s) and the source, provide a link to the Creative Commons license, and indicate if changes were made.

\section{References}

Azzedine D, Conlon Martin J (2016) Operational performance of textured journal bearings with a contaminated fluid. Tribol Int 93:377-389

Bouyer J, Fillon M (2011) Experimental measurement of the friction torque on hydrodynamic plain journal bearings during start-up. Tribol Int 44:772-781

Chen S-K, Chou H-C, Kang Y (2012) Stability analysis of hydrodynamic bearing with herringbone grooved sleeve. Tribol Int 55:15-28

Hassan E, Rasheed E (1998) Effect of surface waviness on the hydrodynamic lubrication of a plain cylindrical sliding element Bering. Wear 223:1-6

Kagohara Y, Takayanagi S, Haneda S, Fujita M, Iwai Y (2009) Tribological property of plain bearing with low frictional layer. Tribol Int 42:1800-1806
Korzyński M (2009) Relief making on bearing sleeve surface by eccentric burnishing. J Mater Process Technol 209:131-138

Martin FA, Garner DR (1983) 4 design of plain bearings use of bearing data design charts. Tribol Ser 8:45-79

Michalak R, Wójcicki R (2012a) Experimental investigation into tribopairs journal sleeve of journal bearing. Mach Dyn Res 3:53-64

Michalak R, Wójcicki R (2012b) Tribological research of transverse sliding bearings. TTS Tech Transp Szyn 9:2707-2715 (CDROM)

Michalak R, Wójcicki R (2013) Experimental research of a journal sleeve wear in radial bearings. Autobusy Tech Eksploat Syst Transp 3:645-654

Rahmani F, Jayanta K (2016) Performance behaviour of ellipticalbore journal bearings lubricated with solid granular particulates. Particuology 27:51-60

Tala-Ighil N, Fillon M (2015) A numerical investigation of both thermal and texturing surface effects on the journal bearings static characteristics. Tribol Int 90:228-239

Wang L, Lu C (2015) The effect of viscosity on the cavitation characteristics of high speed sleeve bearing. J Hydrodyn 27:367-372

Wójcicki R, Strzelecki S (1999) Measurement of tribological characteristics in the research of journal bearing materials. Lubr Eng 55:31-35 